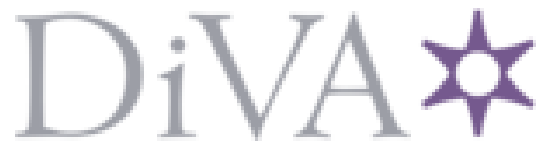

http://www.diva-portal.org

\title{
Postprint
}

This is the accepted version of a paper published in Philosophy, Psychiatry, and Psychology. This paper has been peer-reviewed but does not include the final publisher proof-corrections or journal pagination.

Citation for the original published paper (version of record):

Jeppsson, S. (2021)

Psychosis and Intelligibility

Philosophy, Psychiatry, and Psychology

Access to the published version may require subscription.

N.B. When citing this work, cite the original published paper.

Permanent link to this version:

http://urn.kb.se/resolve?urn=urn:nbn:se:umu:diva-182811 


\title{
Psychosis and Intelligibility
}

\author{
ABSTRACT \\ When interacting with other people, we assume that they have their reasons for what they do \\ and believe, and experience recognizable feelings and emotions. When people act from \\ weakness of will or are otherwise irrational, what they do can still be comprehensible to us, \\ since we know what it is like to fall for temptation and act against one's better judgment. Still, \\ when someone's experiences, feelings and way of thinking is vastly different from our own, \\ understanding them becomes increasingly difficult. Delusions and psychosis are often seen as \\ marking the end of intelligibility. In this paper, I argue first for the importance of seeing other \\ people as intelligible as long as this is at all possible. Second, I argue, based on both previous \\ literature and my own lived experience, that more psychotic phenomena than previously \\ thought can be rendered at least somewhat intelligible. Besides bizarre experiences like \\ illusions, hallucinations and intense feelings of significance, I also explain what it is like to lose \\ one's bedrock, and how this loss impacts which beliefs one has reason to reject. Finally, I give \\ an inside account of some disturbances of reason, and show that there are important similarities \\ between certain psychotic reasoning problems and common non-pathological phenomena. \\ Keywords: delusion; lived experience; empiricist account; two-factor account; understanding; \\ bedrock
}




\section{Psychosis and intelligibility}

Like many scholars before me, I argue for a duty to assume, as far as possible, that other people are intelligible. Unlike many scholars before me, I argue - drawing on my lived experience that intelligibility can be extended further into delusions and psychosis than commonly thought.

\section{INTRODUCTION: INTELLIGIBILITY AND INTERACTION}

We often try and sometimes succeed to understand other people: how they feel, their reasons for action, and what they base their beliefs on. Understanding others does not require that they are rational in any strong sense of the word. We can understand someone who acted impulsively or was weak-willed, since most of us have been there and know the feeling. Of course, to which extent we really try to take up other people's perspective - try to see things from their point of view and appreciate what things were like for them - varies a lot depending on our relationship with them. A brief interaction with a stranger is different from a close relationship with a friend or lover. Still, even in the case of the stranger, we habitually assume that they have reasons for what they do and believe, as well as recognizable feelings and emotions.

In this paper, I will use the terms intelligible and intelligibility when discussing this crucial element of regular human interaction. Intelligibility, as I use it, is a scalar notion. I define full intelligibility as follows:

FULL INTELLIGIBILITY: An action/belief/experience/etc. is fully intelligible to you if and only if it is possible for you to place yourself in the shoes of the agent/believer/experiencer/etc.; that is, you have a good grasp of what it was like for them to do/believe/experience this thing, and, if applicable, the reasons they had for their beliefs and/or actions.

Full intelligibility is a mostly ideal notion. Nevertheless, we can be closer or further away from this ideal. Another person and their beliefs, actions and experiences can be more or less intelligible to me. But what are we to do with a person who falls off the scale altogether? 
It is possible to interact with others without trying to understand them, so to speak, from the inside. We can still try to figure out what causes certain behaviors, and influence said behavior by changing the causal factors. Richard Bentall provides a stark example of this approach in his description of behaviorist methods in mental hospitals during the nineteen fifties (Bentall, 2010, pp. 55). A nurse noticed that a schizophrenic patient, who had not spoken for nineteen years, looked at the nurse's package of chewing gum. The nurse then trained the patient to become more active, first by giving him gum when he moved his eyes towards it, later only when he moved his lips, and finally withholding the gum until he spoke and asked for it. This type of operant conditioning can be applied to any species of animal; the trainer need only observe behavior, not understand how the subject feels or thinks.

However, interaction with unintelligible people - or those perceived to be - need not be this extreme. P. F. Strawson (1962) famously distinguished between a participant and an objective attitude to other people. We regard people objectively, Strawson writes, when they cannot participate in normal adult relationships; we do this, for instance, with little children and "hopeless schizophrenics". We do not feel resentment if they wrong us, and we do not argue or reason with them. We can occasionally pretend to engage in an argument or to reason with them, but all we really do is attempting to handle, train or manipulate them in a desirable direction. Strawson acknowledges that there is no sharp border between the participant and the objective attitude; attitudes can sometimes be mixed, or we can slide back and forth between them, but it is still an important distinction.

Thus, there are ways, more or less extreme, of interacting with other people even when they are unintelligible to us. Nevertheless, being seen as unintelligible is tragic. If I am completely unintelligible in the eyes of everyone else, I cannot have any real communication or reciprocal relationships with them. Jeanette Kennett (2009) therefore stresses the importance of trying to find whatever intelligibility, agency and communication there is and hang on to it. However, 
she readily admits how challenging this can be for conditions like schizophrenia. Karl Jaspers even argued that it was impossible to understand 'delusions proper' (Jaspers, 1997, pp. 95-108).

In this paper, I will first explain the notion of intelligibility more thoroughly, then argue for its importance, and finally show that a broader range of psychotic and delusional phenomena than commonly assumed can be intelligible. This paper is not the place to delve into discussions of how to define delusions more precisely; every definition in the literature is controversial and contested. But very roughly, 'delusion' refers to bizarre pathological beliefs. ${ }^{1}$ Psychosis, on the other hand, describes a state of mind - frequently disorienting and frightening - in which it is difficult to distinguish the real from the imaginary. I will argue based on both existing literature and my own lived experience. When discussing impaired reasoning, I rely mostly on the latter.

I am but one person, and my own experiences necessarily limited. Other people might have experienced psychotic states differently. Furthermore, I have a notable lack of negative symptoms, and can therefore not speak to what it is like to experience those. Nevertheless, there is one important advantage in looking back and analyzing one's own experiences, rather than relying on other people's testimony. Remembering and describing still involves some interpretation, but one big interpretative layer has been removed when a scholar draws on their own experiences rather than others'. In particular, my account of what it is like when reason itself is affected, should fill a lacuna in the existing literature.

\section{DEFINING AND EXPLAINING INTELLIGIBILITY}

Since the term intelligibility will play such a crucial part in this paper, and since I use it as a term of art, I will spend the first part of the paper explaining more thoroughly what I mean by it.

\section{INTELLIGIBILITY, REASONS AND RATIONALITY}

In my above stipulative definition of full intelligibility, I included both grasping what it was like for the other, and, if applicable, their reasons. We often consider irrational behavior fairly 
intelligible in the sense that we can grasp what it was like for the agent, even if there is no satisfying reasons explanation for what they did (I will come back to this). Furthermore, intelligibility, as I use the word, is both scalar and relative. A person can be far from fully, but still somewhat, intelligible to me. People can also have an easier or harder time understanding each other depending on their similarities and differences; a person who is only somewhat intelligible to me could be highly intelligible to you.

Let us first look at non-pathological examples. Suzy, Anna and Tom are friends. Tom spends a lot of time and energy trying to get his hands on tickets to a big football match. Since Tom is a football fan and roots for one of the teams, he has easily discernible reasons for chasing after tickets. Even if the tickets are sold out already, his behavior remains intelligible if he does not know this, but believes there might be tickets left to buy somewhere.

Still, spending as much time and energy on this pursuit as Tom does can be more or less intelligible to other people. Anna can easily place herself in Tom's shoes, since she is a football fan too. Suzy has no interest in sports whatsoever, making it harder for her to understand how someone can be so excited about football. Tom's behavior is thus more intelligible to Anna than to Suzy. Still, Suzy loves science fiction and spends time and money on that hobby; she can tell herself that football is to Tom what science fiction is to her. His behavior is thus still intelligible to her, albeit not quite as intelligible as it is to Anna.

Next, suppose that Suzy decides to exercise more; she will go for a run three times a week. She has all the usual reasons for this kind of decision, and feels motivated when she thinks of her long term plans to improve both her health and looks. Despite this, she ends up on the couch binging TV shows on Netflix over and over again, instead of going running. Suzy is irrational, and the lively philosophical debate about weakness of will shows that it is difficult to even explain what goes on here in terms of reasons, judgments and desires. Yet, in everyday, nonphilosophical contexts, we are hardly baffled by her behavior. It is intelligible to most of us in 
the sense that we know what it is like to omit doing something because one does not want to, at least not now, despite judging that one really should.

In a paper on the possibility of understanding people with schizophrenia, Mads Gram Henriksen (2013) distinguishes between the ordinary, psychological understanding of another person, where we interpret what they do in terms of beliefs, desires and motivations under Davidsonian rationality constraints, and a special philosophical understanding, where we try to grasp what it is like to suffer from bizarre and altered experiences, and which consequences they might in turn have for affect, language use and action. I do not deny the difficulties involved in trying to understand experiences radically different from our own, but it is nevertheless worth pointing out that there is also a lot of common, unremarkable behavior that we understand in terms of what it was like rather than reasons. Suzy's weak-willed binge watching provides one example; common phobias, like fear of spiders, another. Unless it is extreme, we do not tend to see arachnophobia and resulting behaviors as particularly mysterious. Tom shrieks and jumps back whenever he sees a large spider approaching him, despite knowing that there are no dangerous spiders where he lives, and recognizing his own behavior as irrational. To Anna, who is afraid of spiders herself, his shrieking and jumping is highly intelligible; to Suzy, who is utterly unafraid of spiders, it is less so. Still, even Suzy knows what fear and shock feels like, and that these feelings naturally give rise to such behaviors. The fact that Tom acts irrationally, without reason, does not entail that he is unintelligible to everyone else, or that some very special kind of philosophical understanding is required.

Since both actions done from ignorance - like Tom's ticket chase when they were sold out already - and irrational behavior can be intelligible, intelligibility can come apart from moral responsibility and autonomy. To which extent people suffering from serious mental illness can 
still be autonomous and responsible must thus be left for other papers. Nevertheless, intelligibility is important in its own right, for reasons clarified later in this paper.

\section{INTELLIGIBILITY AND CAUSES, PSYCHOLOGICAL AND NEUROLOGICAL}

An explanation of an agent's beliefs, behavior and so on can only provide intelligibility, in the sense discussed here, if it is couched in psychological terms. Fortunately, psychological explanations can be perfectly compatible with neurological ones. Often, a neurological explanation simply approaches mental events from a different perspective or angle than the psychological one does. Neurological explanations can point to causal mechanisms, but on their own, they do not say anything about the subject's reasons and experiences. (This does not mean that they are bad explanations; which explanation is the best one depends on context and what

we are looking for.) When people communicate how they feel in neurological terms - e.g., people who say things like "ugh, my serotonin hit rock bottom today" - others can understand how they feel only because of shared assumptions about how low serotonin causes (or perhaps is identical with) low mood, assumptions that bring psychology back into the picture.

Although couching an explanation in psychological terms is necessary for providing intelligibility, it is not sufficient. First, it is at least arguably possible that explanations which refer to wholly subconscious beliefs and desires fail to offer intelligibility; for starters, it might be impossible to picture what it is like to have a desire that you are not the slightest bit conscious of. Second, even if an explanation uses psychological rather than neurological terms, it can be mechanistic and purely causal in nature. If someone claims that delusions are partially caused by an inability to assess probabilities, this explanation is couched in psychological/mental terms. It is not about, say, neurotransmitters going awry, but an inability to successfully perform a certain kind of mental action. Yet, it does not provide intelligibility, at least not on its own: it says nothing of what it is like when these probability assessments allegedly go off the rails, or 
about any reasons the subject might have, or think they have, for assessing probabilities differently.

\section{ASSUMING HYPOTHETICAL INTELLIGIBILITY}

As previously stated, intelligibility is relative. Therefore, actions, beliefs, and so on that are in principle intelligible to the right person with the right information, can yet fail to be intelligible to me. If another person is radically different from me, this makes placing myself in their shoes difficult, perhaps to the point of impossibility (much as in the case of Nagel's famous bat: Nagel 1974). A lack of information can also prevent intelligibility. If I cannot communicate with the other, there might be no way to remedy this lack either. Furthermore, it is important to admit when intelligibility breaks down; I ought not to fool myself into thinking that I fully understand another when I do not. Even though it is possible that I understand another better than they understand themselves, appropriate humility is important; explaining to another person the supposed real reason they did what they did can easily turn patronizing and, depending on the initial power dynamics, oppressive.

Nevertheless, I can still assume that the other person is hypothetically intelligible: I assume that if I had had more information, communication, similar experiences, etc., it would have been possible for me to understand what it is like for them and see their reasons. In everyday life, we do this all the time. We see someone do something and we have no idea why, but we assume they had their reasons. We see someone bouncing down the street smiling from ear to ear, and we assume some happy event brought their mood up, even though we have no idea what it was.

Suppose that Anna trains her dog for an upcoming tracking contest. When preparing an exercise, she slowly walks across a wide field, placing small wooden sticks with her scent on them twenty to thirty meters apart. Tom, who knows nothing about dog tracking contests, sees her doing this, but has no idea why. Her behavior looks incomprehensible to him, but he assumes that it would make sense to him if he knew more. A few weeks later, he hears Anna 
talking to her dog friends about winning the contest and moving up a level in the sport. She uses so much special dog lingo that Tom cannot really comprehend what she says, except that she is happy for dog related reasons. Still, he assumes that he would have understood her if he was part of her group and had the relevant experiences.

In everyday and non-pathological contexts, it is natural for most people to assume, as Tom does with Anna, that the other is hypothetically intelligible - someone you could understand if you knew more about them, had more similar experiences to draw on, and so on. When encountering someone with a serious mental illness, it is easier to slip into the assumption that not only do you fail to understand them: there is nothing there to understand. However, in the following section, I will argue for a duty to try to understand others, to try to see them as intelligible in the sense discussed here, as far as possible, and to assume hypothetical intelligibility when actual intelligibility breaks down.

When Tom assumed that Anna was hypothetically intelligible, he also assumed that if they had the time, she could explain to him all about this dog business she is involved in, what the rules are and how it works. When facing a seriously mentally ill person, there can be far higher barriers to understanding, not present in the Tom-Anna case. A paranoid person might not want to explain why they think a conspiracy threatens them, since they fear their interlocutor might be part of it. However, they might still have reasons for this belief; they might not be very good reasons, and they might stem from experiences that are in turn illusory, but reasons nevertheless.

\section{HYPOTHETICAL INTELLIGIBILITY AT THE LIMIT}

At the end of the line, we find the radical or second-order empathy discussed by scholars like Giovanni Stanghellini (2013) and Louis Sass (2013). When interacting with schizophrenic patients, they write, we might face people whose experiences are so utterly unlike our own that it becomes impossible to place ourselves in their shoes and see things from their point of view. ${ }^{2}$ 
However, they stress that someone else's unintelligibility to us does not imply that there is nothing to understand within this person's experience. There remains something that it is like to be schizophrenic, but it is vastly different from what it is like to be mentally healthy, and experiencing the world and one's own mind in the normal way. We can, however grasp this fact on an intellectual level, and this realization enables us to have empathy of sorts even with the very different.

Mohammed Abouelleil Rashed (2013) harshly criticizes the thesis that we should appreciate how utterly different schizophrenic people are from others. All people have both similarities and differences, and we can always choose what to focus on. If we focus on the extent to which an already marginalized and stigmatized group is different from other people - extremely different, even - this is likely to have all kinds of detrimental effects.

I believe Stanghellini and Sass do make an important point. If I encounter a person so different from myself that they remain unintelligible to me however hard I try to understand them, it is important to remind myself that there is nevertheless something that it is like to be that person, even if I do not know what it is. Nevertheless, Rashed makes important points too. It is often detrimental to be regarded as extremely different from others and impossible to understand, which is why we ought to try to understand others and try to see them as intelligible, as far as we can. I will further elaborate this point in the following section.

\section{INTELLIGIBILITY DUTIES}

Any duty to spend time and effort on trying to understand others must be pro tanto - meaning it can be overridden by other considerations. Self-care is an obvious one. Struggling to understand someone can be exhausting. Temporarily, we might have to take up a more detached stance, where we mostly consider how to 'handle' the other person, in order to avoid burnout (Kennett, 2009). There are also limits to how much time and mental effort psychiatric staff can spend on one patient without depriving others. Finally, 'ought' implies 'can' - we can be 
obligated to put time and effort into something, rather than giving up prematurely, but we cannot be obligated to do that which is impossible for us.

With these limits stated, I will argue that we nevertheless have a moral duty to see people we interact with as intelligible, insofar as we can. There are a number of reasons for this; one might say this duty is morally overdetermined.

\section{REASONS FOR DUTIES OF INTELLIGIBILITY}

\section{PRESERVE RELATIONSHIPS}

People suffering from serious mental illness frequently lose relationships and friends as a result, and this, in turn, can lead to a deterioration of identity and further aggravate the disorder. On the flip side, interventions by significant others, when those are still around, can mitigate a lot of the negative effects of mental illness (Kennett, 2009, p. 103; Watts and Priebe, 2002, p. 446). As previously stated, there are ways to interact with people unintelligible to oneself. It need not take extreme, behaviorist forms either; we can still talk to people we deem unintelligible, and retain a semblance of normal human relationships. Nevertheless, when someone becomes completely unintelligible to us, there is a sense in which we no longer communicate for real. When I have absolutely no idea what goes on inside another and how things seem to her, they remain isolated from me even if we are in physical proximity. This gives us a strong reason to try to understand as far as possible, rather than giving up prematurely.

\section{ENABLE EMPATHY AND PREVENT ABUSE}

In her largely autobiographical Faces in the Water (1961), Janet Frame tells the story of her long stay in a New Zealand mental institution in the nineteen fifties and sixties. She starts out in the nicer ward, but is later moved to a far worse one with the supposedly hopeless cases. At first, she was told and accepted that the patients there did not suffer from their mistreatment and dismal living conditions; they were allegedly too insane to notice what happened to them. When moved to the terrible ward herself, Frame found out how wrong she had been. 
Once we see someone as completely beyond intelligibility, and their behavior as explicable only in causal, mechanical terms, it is likely all too easy to rationalize mistreatment in this way. As already mentioned, Stanghellini and Sass stress that even when someone is too mentally ill to be intelligible to others, there is still something that it is like to be them. Just because you cannot reach someone or communicate with them, you are not entitled to conclude that they are akin to a philosophy zombie, with no actual experiences, feelings or emotions at all.

However, this bare bones realization and subsequent bare bones empathy might only take us so far in consideration for other people's interests. Philosophers as diverse as Iris Murdoch and Christine Korsgaard have stressed that our values, concerns and how we see other people shape what stands out to us and what we attend to (Murdoch, 1985; Korsgaard, 1996, pp. 179-180). In theory, you might act so as to promote other people's happiness and prevent their distress based on nothing more than the acknowledgement that they are sentient beings endowed with moral status, but in reality, more is often required in order to even notice people's various interests and needs. Quoting psychologist Graham Reed, Brendan Maher goes as far as saying that empathy with delusional psychiatric patients is made possible when we realize (as he argues is the case) that non-delusional people likely would have believed and acted the same as the delusional, if only they had suffered from the same weird experiences (Maher, 1999; Reed, 1974, p. 154). The claim that this fairly high level of intelligibility is required for empathy might be too strong, but it can nevertheless be true that seeing others as intelligible greatly facilitates empathizing with them and paying attention to their wants and needs.

Furthermore, a number of philosophers have argued that accountability plays a central role in our moral practices (e.g., Darwall 2006; Scanlon 1998). The full scope of morality might be wider; it might include matters like, e.g., a non-instrumental concern for nature, even though 'nature' cannot hold us to account. But strong duties and rights are located within the realm of persons interacting with other persons, who can demand things from us, who can hold us 
accountable for what we do, and to whom we can justify our behavior or fail to do so. Regardless of the extent to which one agrees with this normative view, there is surely an important psychological insight here: objections and demands for justification can often move us in a way that more abstract moral principles rarely do.

However, objections and demands will have no effect unless they are perceived as such. On the one hand, Darwall writes of how even non-verbal cries from babies or dogs can be perceived as complaints and objections, since we can see them as "proto-persons" (Darwall 2006, p. 29). On the other hand, people sometimes refuse to hear a verbal objection as such; they might instead consider it a mere symptom, the kind of noise patients with this diagnosis tend to make (Bentall, 2004, pp. 496-498; see also Arpaly, 2005, p. 297).

\section{THERAPEUTIC GOALS}

Carl Rogers stressed early on that therapeutic success requires a therapist who understands and empathizes with their patient, and subsequent research has supported this (Rogers, 1957; 1965; Kirschenbaum \& Jourdan, 2005). More recently, psychiatrist Rachel Upthegrove and anonymous former psychiatric patient S.A. likewise write of how important it is to empathize with the patient's experiences and try to "walk fully in someone else's shoes", as hard as this is. Without this effort on part of psychiatric staff, there is a higher risk for suicide. Neither pharmacological nor psychological interventions might be accepted, or if accepted, not effective. (Upthegrove and S.A., 2018, pp. 20-21). This is further echoed in Watts and Priebe's (2002) interviews with psychiatric patients in Assertive Community Treatment. Experiences of previous, traumatic coercive care, but also ongoing experiences of doctors and social workers who fail to listen to them or understand them, seemed a more common cause of non-compliance than lack of insight into their mental illness.

Upthegrove and S.A. write of staff understanding and empathizing with patients, but patients can also benefit from attending to similarities between themselves and mentally healthy people. In Cognitive Behavioral Therapy for psychosis sufferers, the patient is encouraged to notice 
important similarities between their thoughts and behavior and that of non-psychotic people. Patients improve when they realize they are not quite as odd as they previously thought (Bentall, 2004, p. 508). Stammers and Pulvermacher (2020) draw the same conclusion from holding philosophy workshops with psychiatric patients, where they engaged in philosophy of mind, epistemology and critical thinking exercises, noting important similarities between psychotic and ordinary thinking.

\section{DECREASING STIGMA}

Focusing on society at large, and the stigma attached to psychosis disorders, sufferers' situation might improve if they were generally considered at least hypothetically intelligible.

Numerous studies have found that embracing biological (e.g., genetic, neurological) explanations of mental illness correlates with increased stigma, at least along some of the commonly measured dimensions (Angermeyer \& Matschinger, 2003; Harré \& Read, 2001; Schnittker, 2008; Pescosolido, Martin, Long, Medina, Phelan, \& Link, 2010; Loughman \& Haslam, 2018; Kvaale, Haslam \& Gottdiener 2013). This runs contrary to the popular belief that we can decrease stigma by promoting the view that mental illnesses are physical disorders of the brain.

Biological explanations of group differences have a general tendency to promote acceptance of stereotypes; researchers believe this is the main reason for the problematic correlations found. However, Loughman and Haslam (2018) also mention the possibility that biological explanations are associated with loss of control, and subsequently danger and unpredictability. This hypothesis gains further support from Eddy Nahmias' research on moral responsibility intuitions (Nahmias, 2011). As previously stated, many neurological-biological explanations of behavior are compatible with psychological ones; they merely explain behavior on a different level or from a different angle. Laypeople, however, tend to believe that a neurological explanation of behavior always imply that agency was bypassed: either I chose to do something for reasons, or else my brain made me do it. 
Of course, psychotic people can sometimes lose control. For instance, if I experience my agency as being bypassed, since I suffer from thought insertion or other bizarre passivity experiences, the idea that I cannot control myself could easily become self-fulfilling. I might not be able to stop doing something, precisely because I have no experience of doing it in the first place. However, this lack of agency could still be circumscribed - I might still try to deal with my inserted thoughts or involuntary movements in various indirect ways, and exercise my agency in how I do this.

It would be good if people in general understood philosophy of mind better, and realized that an explanation can be biological or neurological without necessarily bypassing agency. But at least in the short term, focusing less on biology and more on intelligibility-providing explanations might be the most efficient way to decrease stigma and the prejudice that most psychosis disorder patients are out of control and dangerous.

\section{RESPECT}

So far, the focus has been on consequences: for relationships, empathy, treatment, therapy and stigma. We might also think there is something intrinsically wrong with regarding and treating people as unintelligible, and thus explicable only in mechanistic terms, as if they were malfunctioning objects. Kennett suggests as much when she, referencing Strawson and his participant-objective distinction, writes:

Now, as beings with the goal of autonomy - as beings constitutively concerned with discovering and acting for reasons-Kant believed that persons had intrinsic worth and dignity and as such were never to be used merely as means. To treat a person as an object is clearly to mistreat them. The demand for respect and goodwill in our dealings with each other is, in the first place, the demand that we approach each other from within the participant stance. It is minimally the demand that we do not ignore or undermine each other's agency (Kennett, 2009, p.111).

When Kennett writes about approaching each other from "within the participant stance", she does not mean we should always hold each other responsible, and react with resentment when 
wronged. Much of her paper argues for the importance of teasing apart on the one hand common blaming practices, which she agrees should often be suspended when interacting with severely mentally ill people, and on the other hand the kind of reciprocal interaction and honest communication that Strawson also builds into his participant attitude. To be treated as someone who cannot be reasoned with, only (as Strawson puts it) manipulated and handled, is inherently problematic. Even if sometimes unavoidable, it is not an approach that should be taken lightly.

\section{EMPIRICIST EXPLANATIONS}

It has been argued that delusions are intelligible only if they can be explained in an empiricist way, bottom-up - unusual experiences come first, and give rise to unusual beliefs (e.g., Maher, 1999). Top-down or rationalist explanations, on the other hand, invoke a supposed impairment of reason. The impairment causes incomprehensible beliefs to pop up, and those in turn color the person's experiences in bizarre ways (Campbell, 2001). Alternatively, the top-down explanation might be presented as a complement to the bottom-up one, in a so-called two-factor account (Davies et al., 2001). Unusual experiences provide the psychiatric patient with prima facie reasons for unusual beliefs, but we must postulate a "second factor", some impairment of reason, to explain why they accept and retain their delusions.

Considering how important intelligibility is, it would be tragic if the following two claims were true: Many delusions and other psychotic phenomena can only be explained by invoking, at least in a complementary role, reasoning impairments, and such impairments undermine intelligibility.

In the following subsections, I will first discuss bottom-up, empiricist explanations of various delusions that can render them intelligible, and see how far this takes us. Next, I will draw on my lived experience to argue that an impaired faculty of reason can be at least somewhat intelligible as well. 


\section{BELIEVING WHAT YOU SEE}

There is certainly something to Maher's claim that strange beliefs and behavior can be made intelligible when we learn that they arose from bizarre experiences. We can see as much when looking at fantastical fiction.

Neo, the main character in the science fiction movie the Matrix, initially believes that he lives in an apartment, works with computers in an office, travels from his apartment to his office each day, and so on. Neo's beliefs are, in fact, radically out of touch with reality (the reality of the movie, that is). In reality, he spends all his time lying in a pod, while machines feed perceptual experiences straight into his brain. Having the kind of life he envisions is impossible, due to the world being largely destroyed and taken over by machines. Still, we do not find Neo unintelligible in the beginning of the movie, merely because all his beliefs are false, even impossible. We understand his beliefs of living in an apartment, working with computers and so on as natural responses to his (hallucinatory) experiences.

Likewise, in the Japanese horror movie Dark Water, main character Yoshimi Matsubara gradually comes to believe that her daughter is pursued by the ghost of a dead girl. Initially, she seeks natural explanations, but as evidence of something supernatural gradually crops up, she eventually realizes (to her terror) that the ghost is real. When watching this type of movie, we do not think the main character turns incomprehensible the moment they accept the existence of supernatural forces; that they do makes perfect sense to us. Of course, Yoshimi Matsubara lives in a world where ghosts exist. But just like us, she has no way of stepping out of herself and see what her world is objectively like, apart from her experiences of it. Just like us, she bases her beliefs on what she sees, hears, reads about, and so on. When everything points in the direction of an actual ghost, a ghost belief eventually becomes intelligible.

Maher argues that a psychiatric patient with delusional beliefs as out of touch with reality as Neo's and as extraordinary as Matsubara's can be intelligible for the same reason as these characters' beliefs are intelligible; just like these characters, and just like all of us, the patient 
forms beliefs based on experience. Maher makes this argument for several types of named delusions from the psychiatric literature, like Capgras, where the sufferer believes someone close to them has been replaced by an impostor.

Capgras delusion is often caused by a stroke and subsequent brain damage, but Maher stresses that it nevertheless need not bypass normal reasoning capacities. The proximate cause is likely a lack of normal response from the autonomic nervous system when the sufferer sees, e.g., their spouse's face (Ellis \& Young 1990). It has been argued that there must be more to this story; if someone does not feel the way he normally does upon seeing his wife, it is a strange leap to conclude that she has been replaced by an impostor (Glover, 2014, p. 154; Campbell, 2001). Other scholars reply that we need not be conscious of what goes on in our autonomic nervous system (Davies et al., 2001, p. 140; Coltheart, Menzies \& Sutton 2010). The Capgras patient might not conclude that his wife has been replaced because he noticed feeling differently; rather, his experience might be that of seeing a stranger who looks very similar to his wife, but not quite right, and yet claims to be her.

This seems plausible to me. I have no experience of Capgras, but I frequently suffer from seeing a stranger rather than myself in the mirror. Usually, with enough "bedrock" intact - see the Rhodes and Gipps discussion later in this paper - I can disregard the experience as illusory. Still, this requires a lot of mental effort, precisely because the experience is not that of seeing my face in the mirror but feeling differently about it. Rather, when this happens, I experience looking at a face in the mirror that is very similar to mine, but nevertheless does not look quite right.

Granting that the experience $i$ s that of seeing a stranger, it remains to be explained why some people accept the experience as veridical. For virtually every delusion, there are people who seem to have the same experience, and yet consider it illusory. Maher believes this can be accounted for by the varying duration and intensity of illusions and hallucinations; people can 
reject weak and/or fleeting experiences, but cannot help taking them at face value when they are intense enough and/or continue for long enough. This is so even when they fully realize how incredible their claims sound, and admit they would not have believed someone else telling them the same story (Davies et al., 2001, pp. 149-150).

One might still object that however intense and prolonged a bizarre experience is, a rational person should be able to dismiss it as illusory if there is ample evidence that, e.g., the woman who says she is their wife really is. I do believe Maher makes an important point; I have found that it is difficult and requires much willpower not to trust your own experiences when they are intense and prolonged enough. Furthermore, a delusion might not come alone, and we do not evaluate our beliefs in isolation.

\section{ERODED BEDROCK}

Rhodes and Gipps (2008) argue that an upset "bedrock" (term coined by Wittgenstein, 1969) or "background" (from Searle, 1983) plays an important part in delusions that seem highly bizarre to others. People normally have a large and highly interconnected cluster of beliefs about themselves and the external world that they take for granted and never question. Yet, they cannot prove or argue for this cluster; the best they could do, if questioned, would be to prove one of the beliefs by reference to the others, but the cluster as a whole is simply taken for granted. Rhodes and Gipps give a few examples of bedrock beliefs such as 'I have a body', 'There are physical objects', 'Tables and chairs do not think', 'I am human', 'I cannot pass through solid objects', 'There are many other people in the world' (Rhodes \& Gipps, 2008, p. 298). When absolute trust in this belief cluster dwindles down, all kinds of strange ideas can take hold.

Campbell (2001) also makes use of the bedrock concept, but in a different way. He writes that the delusion itself might acquire the status of bedrock belief to the subject. Perhaps this is an accurate description of some delusional cases. However, Campbell's delusion-as-bedrock- 
belief should not be confused with Rhodes and Gipps' loss of bedrock, which better fits my own experience. Loss of bedrock can clearly play the role of a second factor in a two-factor account, and explain why some people fail to reject their bizarre experiences as illusory.

Rhodes and Gipps discuss psychiatric patients with delusions even more bizarre than Capgras (the idea of people being replaced by impostors is at least familiar from fiction), and show how a loss of bedrock could explain why they are retained. One woman believed she had rubbed her legs so much that they turned male; she was seriously distraught by this perceived partial sex change. Rhodes and Gipps stress that we immediately just know that this is impossible, because we just know how things work and what causes what. Sure, we can attempt a scientific explanation of the impossibility of sex change via leg rubbing, but for most of us, that explanation would quickly turn jumbled if we were pressed for details. Even for someone biologically savvy enough to provide a proper scientific explanation, it would be secondary to just knowing that this cannot happen.

If your bedrock erodes, if you find yourself questioning things you previously took for granted, so that you no longer just know a whole host of propositions, all kinds of hypotheses suddenly pop up as live possibilities to consider. If you used to believe that $\mathrm{P}$ was out of the question because $\mathrm{Q}$ proves that $\mathrm{P}$ is impossible, only to realize that you lack evidence for $\mathrm{Q}$, you might suddenly lack reason to reject P out of hand (I use 'reason' in an internalist sense here, meaning that there is nothing psychologically accessible to you, nothing in your belief system, which provides you with a reason to reject $\mathrm{P}$ anymore).

Rhodes and Gipps' account of psychotic people's epistemic situation differs radically from Glover's. Glover (2014, pp. 152-159) notes that psychotic patients often embrace ideas similar to those found in texts written by philosophical skeptics (see Reimer, 2011, for further comparisons). Nevertheless, he believes that the former fail to see how improbable these skeptical hypotheses really are. He writes that we have good evidence for, e.g., the existence of 
an external world; the skeptic simply sets the evidential bar too high, thinking that no realistic amount of evidence suffices (ibid, p. 153).

However, this is not how skeptics normally argue. They do not claim that the bar for sufficient evidence should be raised towards the sky; rather, they try to show that we lack evidence for, e.g., the existence of an external world, according to ordinary evidential standards. Evidence and arguments must not presuppose what ought to be proved. But, the skeptic says, all our supposed evidence for an external world presupposes what ought to be proved (Steup \& Neta, 2020; see also Feldman, 2004, pp. 267-269, on skepticism about knowledge and freedom).

This is an important insight, and I believe often crucial for appreciating the extent to which delusional people can still be intelligible. The content of delusional beliefs are not impossible or improbable in themselves (at least not unless the content is an actual logical contradiction); they are only impossible or improbable given the truth of a whole host of other propositions, which ultimately rest on unquestioned bedrock beliefs. Remove the subject's bedrock, and they no longer have any reason to reject the delusions.

I once found myself in a state where my experiences oscillated between, so to speak, normal and bizarre. ${ }^{3}$ I had a hard time knowing which experiential set to trust. I would have needed a bedrock to decide between them, but mine was currently eroded. My psychiatrist tried to argue with me in favor of the former, "normal" set, and standing on a firm bedrock himself (as I assume he was), his arguments must have seemed convincing to him. Since my own had eroded, it was painfully obvious to me that any supposed argument he gave already presupposed that "normal" experiences are the veridical ones and the "normal" worldview overall true. The impossibility or near-impossibility of arguing for any empirical proposition whatsoever without such presuppositions is exactly why far-reaching skepticism is still debated and taken seriously 
in epistemology, even though only a minority embrace it. Other psychiatric patients could face this problem too, even if they cannot articulate it in the way I just did.

Still, if an eroded bedrock has the drastic effects just described, one might wonder why philosophical skeptics who stress the lack of evidence for bedrock propositions such as 'there are physical objects' and 'I am human' do not fall prey to psychosis as well. Now, there is some anecdotal evidence to the effect that skeptics sometimes are deeply disturbed by their own theses. When they are not, it might be because their doubts are purely academic; they still, in some sense, feel their feet resting comfortably on solid rock. Perhaps, as Hume said, they forget all about skepticism as soon as they play backgammon with their friends (Reimer, 2011).

So how intelligible can bedrock loss be, to someone who never experienced this? As shown by my personal anecdote, when someone loses their bedrock, trying to argue with them will be futile. For most non-psychotic people, it might also be impossible to vividly picture what it would be like. But intelligibility, in my sense, is also about understanding people's reasons for actions and beliefs. When you lose your bedrock, you simultaneously lose most of your epistemic reasons. This is still an important complement to any neurological explanation of what went on in, for instance, my own brain, when my psychiatrist tried to argue with me in vain.

\section{SIGNIFICANCE}

Besides hallucinations, illusions and bedrock erosion, strong feelings of significance, or FoS, can play an important part in producing elaborate delusions. Maher (1999) stresses that FoS the sense that something is different, someone looks different, something is not quite right - are common in the general population too. When you sense that something is different or a little off, this prompts you to look for an explanation. He writes that schizophrenia sufferers often have strong FoS about all kinds of things, but since there are no actual explanations outside of their pathology, they will invent explanations, and thus delusions arise. 
Maher is surely right that there are comparisons to be drawn between pathological and nonpathological FoS. Still, based on my own experience, I believe movie comparisons can better explain what it is like to have very strong and ominous FoS.

In movies, camera angles and musical score often show the audience that some person or object is significant; perhaps as a threat, or a clue to a mystery. When watching a well-made movie, we need not even be conscious of angles and score; we just notice the significance they imply. Quite recently, when under a lot of stress, I had the following experience: I was walking my dogs after dark, down a perfectly normal street with houses and gardens. Suddenly, a house a little further away caught my attention; it looked sinister somehow, threatening. I did not hallucinate; I did not literally experience the house looking bigger and bigger, as when a camera zooms in on something in a movie, nor did I literally hear the kind of threatening musical score used in run-of-the-mill horror movies. Nevertheless, the overall impression I suddenly got was like watching a horror movie where zoom and musical score together unambiguously tell the audience that this is a really scary house. This time, the experience was still fairly easy to shrug off, but as previously mentioned, if one's bedrock crumbles and strange experiences pile up more and more, it is a different matter.

Maher (1999) writes that we should be parsimonious; if delusions can be explained on a purely empiricist basis, without positing reasoning impairments, we should do so. It seems to me that the move from FoS to delusional beliefs is often less straightforward than the move from hallucination or illusion to delusion. Nevertheless, even if all the well-known examples from the literature could be explained without any reference to impaired reasoning in psychosis sufferers, I have my own experiences to draw on. And I can recall my reasoning and inferential skills going off the rails when entering a psychotic state of mind.

In the penultimate section of this paper, I will describe this phenomenon and what it is like. Once again, it might be very hard to picture for people who have never experienced this 
themselves, but it can still be described, and importantly, parallels drawn to common aspects of non-psychotic people's thinking.

\section{THE SEEMINGS OF REASON}

\section{SEEMING VALIDITY, SEEMING EVIDENCE}

Maher stresses that everyone, not just delusional and psychotic people, tend to trust that things are the way they seem: the way they look, sound and so on. Similarly, everyone tends to assume that a line of reasoning that seems valid really is valid, and that something that seems like evidence for something else really is.

When I talk of these seemings, I do not refer to positive or conscious experiences. I do not normally experience that something seems this way or that, only to move on to trusting the seeming and believing it veridical in a second, separate step. On the contrary, trusting one's faculties of perception and reason is normally wholly non-conscious and automatic. My dog currently naps in the armchair. How do I know this? Well, I can see her from where I sit. I do not first note that it looks like my dog lies in the armchair, only to then conclude that she really is there. I just see her, and I know. I go to the library with the intention of returning a book, only to find that it is not in my bag; I must have forgotten it at home. I do not stop at this point to ask myself whether I correctly inferred a best explanation or not. I just accept that the book is back home. As long as nothing indicates that we currently should not trust our senses or our reason, we happily look, listen and infer away, with no need of constantly checking that our senses are reliable and our faculty of reason functions the way it should.

Scholars who write about empiricist or bottom-up explanations of delusions versus rationalist or top-down ones, usually take it for granted that there is an important distinction between on the one hand a psychiatric patient who arrived at bizarre beliefs through normal inferences drawn from bizarre experiences, and on the other hand a patient whose very faculty of reason is distorted. And for all I know, it is possible that they are different on a neurological 
level. However, at least in my own experience, there are important phenomenological similarities. I look in the mirror and see a face subtly different from my own. Normally, we accept what we see as true. If I have enough normal experiences towards which to contrast the illusion, and enough bedrock intact to realize the impossibility of a malevolent entity sneaking up on me via mirrors, I can conclude that what I see is an illusion, not to be trusted. Hanging on to this conclusion requires willpower of a kind not needed in the case of non-threatening, neutral optical illusions like a seemingly bent oar in water, but I can do it. Nevertheless, with an eroded bedrock and all kinds of bizarre experiences piling up, the natural tendency to trust - automatically and non-consciously - what we see will take over. I think about what is happening to me, and draw a conclusion in an illogical manner. If I still reason mostly correctly, albeit with little islands of bizarre inferences here and there, and with a lot of intact bedrock to test conclusions against, I can catch myself being illogical and double-check my own inferences. When everything erodes, there is no longer any sound baseline against which to do this, and so the natural tendency to trust our own reasoning powers will take over. As with perception most of the time, that trust is automatic and non-conscious; it is not accompanied by any meta-thoughts and thinking about our own thinking.

Psychotic reasoning, for me, is not about thinking completely jumbled and random thoughts, while still not seeing the problem. Rather, everything gets amped up; trains of thought and lines of reasoning seem stronger than they actually are. Normally, we can tell the difference between deduction and looser types of reasoning, like numerical induction and inference to the best explanation. Even non-philosophers who never studied these things have some instinct for it. Sometimes a line of reasoning is watertight, leaving no room for doubt, and sometimes it is looser, giving probabilities rather than certainties. We need not consult logic text books to tell the difference; we just do (albeit far from perfectly, of course). However, when sliding into psychosis, an inductive line of reasoning can very much seem like a watertight deduction. 
Therefore, certainties crop up in place of more hesitant beliefs. Furthermore, a train of thought where one association leads on to the next one, can seem like a line of reasoning where the content of the earlier thoughts provide evidence for what comes last.

Suppose I see an odd-looking old car drive by that resembles the one my P.E. teacher drove when I was ten. This makes me think of football, since she often made us play this sport. The thought of football makes me think of my friend Tom, since he is a football fan. I have not seen him for some time, and I wonder what he is up to now. It is perfectly normal for my mind to slide from the odd-looking car to Tom via these intermediate steps, but when non-psychotic, it is clear to me that nothing more interesting goes on. When sliding into psychosis, however, this same train of thought can seem like a line of reasoning, where the odd-looking car driving by indicates something about Tom. The car might be evidence that he is up to something; something relevant to me. He might plan to hurt me, or he might be able to rescue me from some other threat. Induction seems like deduction; a train of thought seems like at least inductive reasoning, where the former steps provide support and evidence for the later ones, rather than just being associated with them in my mind.

\section{PSYCHOTIC STUBBORNNESS}

Everyone who has taught logic or critical thinking knows first-hand that non-psychotic people often err in these areas. Still, one might think that whereas people in the grip of psychosis are impossible to reason with, the non-psychotic will realize that they made an error when this is explained to them. A student of mine encountered the following argument in a textbook: "90\% of all people are right-handed. Therefore, there is a $90 \%$ probability that Bill is right-handed." This argument seemed deductive to the student. I pointed out that a deductive argument's validity cannot be altered through additional information, but in Bill's case, it is clearly more likely that he is left-handed if it turns out that he uses his left for everything from writing to 
playing tennis. After my explanation, the student saw that the argument was not deductive after all.

Still, it is not difficult to find examples of non-psychotic people who cling to their faulty logic with aggressive stubbornness. The famous Monty Hall Problem provides a good illustration of this phenomenon.

Suppose you partake in a game show, where there are three doors on stage, only one of which has a prize behind it. You are told to pick a door, and you choose door one. The host Monty Hall, who knows what is behind each door, does not immediately open it. Instead, he opens door three, revealing there is no prize behind that one. Next, he asks whether you want to stick to door one or switch to door two. To most people, it strongly seems as if switching doors will make no difference. Nevertheless, switching doors doubles your chances. Marilyn vos Savant, labelled "the smartest woman in the world", famously received loads of angry letters when she explained this in a newspaper column (Crocket, 2015). Since vos Savant is a woman, it is possible that sexism played a role in the anger directed towards her. However, male mathematics professor Keith Devlin also reports angry and downright abusive responses when explaining the Monty Hall problem to people (recounted in Comstock, 2013, pp. 72-76). Devlin speculates that people might be particularly passionate about their mistaken probability estimates compared to other logical errors. This was a thought experiment, but probability estimates are frequently important for real-life decisions; people might therefore feel the stakes are high, and become emotional (ibid, p. 76). If this is right, it is no wonder that people stubbornly cling to what seems like valid lines of reasoning in the grip of psychosis, when trying to navigate a seemingly hostile and frightening environment to the best of one's ability. If I think I need my wits to handle my situation, perhaps even to survive, the possibility that my wits cannot be trusted might be too frightening to contemplate. 
It would be hard to design a study such that it measured psychotic stubbornness independently of factors such as eroded bedrock, impaired faculty of reason, and intensity and duration of bizarre experiences. But there is no prima facie reason to suppose that psychotic people always, or even for the most part, are more stubborn than non-psychotic ones who get angry when someone explains the Monty Hall problem to them. If one suffers from some or all of the additional problems discussed in this paper, one likely does not need to be more stubborn than other people in order to be absolutely impossible to argue with.

Non-psychotic people who want to get some inkling of what it feels like when one's faculty of reason goes off the rails, should thus first consider their own feelings of frustration when logic experts provide highly counter-intuitive answers to puzzles like Monty Hall. Next, try to imagine the stakes shooting up. Add on strange and unsettling experiences, and a situation where you cannot take anything for granted and all bets are off (i.e., the eroded bedrock). There you have it.

\section{THE FEELING OF UNDERSTANDING}

Bentall suggests that psychotic people can be seen as amateur scientists, constructing theories to explain their experiences (Bentall, 2004, p. 303). For reasons previously discussed in this paper, the resulting theories will be strange by regular standards: In the grip of psychosis, we have different data to explain (provided by hallucinations, illusions and feelings of intense significance), we might have lost the bedrock that would immediately rule out many hypotheses had it remained, and it might strongly seem to us that loose chains of associations actually provide evidence for a hypothesis. Finally, a theory which is bizarre by ordinary standards, might still be the one that provides a feeling of understanding, to use a term from J.L. Trout. Most of the time, when we think and draw inferences, we do not really have any positive feeling of getting things right - we trust ourselves in the absence of reasons for doubt. But the feeling of understanding, or FoU, is very much a positive experience. 
Trout's aim in his Wondrous Truths (2016) is not to explain psychosis, but the rapid scientific progress that took place in the western world starting with the enlightenment. Even though adherence to sound scientific method is necessary for scientific progress, Trout argues that it is far from sufficient. There have been plenty of scientists in other parts of the world just as intelligent and diligent as those in Europe and North America. However, science largely and inevitably relies on inferences to the best explanation, and which explanation is the best one will always be seriously underdetermined by the data. Still, some explanations make you feel that you truly understand the matter at hand, whereas other explanations do not provide the same emotional satisfaction. Is this feeling a reliable guide to truth? Usually not, Trout says, but there is no way around it. And it can be reliable under the right circumstances. To make a very long story very short, Trout argues that scientists like Newton and Boyle initially lucked out. Their FoUs latched on to theories that were close enough to the truth to lead to fruitful further scientific investigations and theorizing; with some initial luck, a combination of proper scientific method and feeling can snowball to greater and greater discoveries. Nevertheless, that same feeling without the initial piece of luck can lead scientists into dead ends, however methodologically conscientious they are.

The extent to which luck combined with feeling has played a role in the development of modern science is of course controversial; it should be less so that a mere feeling of understanding plays an important role in non-scientists' thinking on scientific matters. Andrew Shtulman (2015), drawing on a large number of previous studies, writes that laymen scientific thinking is heavily constrained by factors that can be found to some (albeit lesser) extent in professional scientists as well. People prefer shallow, unscientific theories that fit their preexisting ideas to scientific explanations that do not feel right and are hard to picture (sometimes because they involve novel or unusual concepts). Shtulman's focus is interestingly not on creationists or flat-earthers. He writes that people who believe in evolution nevertheless often 
have an utterly mistaken (albeit internally consistent) view on how it works, and that nonphysicists think and reason about heat as if it were a substance rather than a process of energy transference. Everyone is prone to accepting explanations and theories that feel right, although what feels right in psychosis might differ a lot from what feels right otherwise.

Most of us can probably recall what it felt like when understanding of a certain subject finally dawned on us. Sometimes, in school or at university, you learn a theory or a method well enough to employ it and pass the tests. Still, you do not feel that it makes sense, that things really click for you, that you totally understand now how it all works and hangs together. At other times, you do feel it; right, I get it now, I understand. We know this feeling can be powerful enough in academic settings where nothing more than your grades are on the line. Now, imagine how much more powerful that feeling of finally understanding what is going on would be, if you found yourself in frightening and threatening circumstances. A loose chain of associations run through your mind, but you experience this as finding evidence for hypotheses and reasons for your beliefs; it seems like your reasoning is sound throughout. When you finally arrive at a theory that explains everything that is happening to you, you feel how everything clicks into place and you finally get it. You might make it after all. ${ }^{4}$

\section{CONCLUSION}

I have argued that we have a pro tanto duty to see other people, as far as possible, as intelligible. Someone's action, belief or experience is intelligible to you if you can grasp what it was like for them, and, if applicable, their reasons. Seeing others as intelligible is important for several reasons: doing so helps preserving relationships, it enables empathy, helps prevent abuse, promotes therapeutic goals, plausibly decreases stigma, and is, finally, important in its own right, since it is disrespectful to prematurely write off other people as unintelligible. I have further shown that even psychotic experiences and thought can be intelligible to a greater extent 
than previously believed, by drawing on my lived experience and pointing out similarities between psychotic and non-psychotic reasoning.

Suppose that you suffer from strange perceptual experiences. Perhaps you hear disembodied voices, see creatures moving around in the corner of your eye, or have bizarre sensations coming from your own body. This is confusing and frightening, and you look for an explanation. At the same time, it strikes you that many of your old beliefs - your bedrock - was actually held on the basis of nothing at all. You used to be so certain, but that certainty is gone now; you have seen how ungrounded all these beliefs were, and you cannot unsee it. But there are some events and objects that stand out to you as, somehow, highly significant - it would make sense to start from there, if you want to figure out what is going on. At least you are smart. You know how to reason and draw conclusions, and this is what you do. Finally, you arrive at an explanation; a theory that perfectly explains everything that was going on. All the pieces of the puzzle slides into place.

In this scenario, you might not handle your strange experiences in the most rational way. Even so, you are a person doing your best in a very difficult situation, just like anyone else would.

\footnotetext{
${ }^{1}$ It is debated whether delusions really are beliefs: see Bortolotti and Miazoni (2015) for an overview of philosophical controversies regarding delusions. I will still refer to them as beliefs throughout, but actually defending this claim lies outside the scope of this paper.

${ }^{2}$ Jaspers writes about how schizophrenic patients usually fail to be intelligible to each other as well, since everyone tends to be caught up in a world of their own, although there are exceptions. (Jaspers 1997 pp. 282-283)

${ }^{3}$ Possibly, much of what is called "double book-keeping" in the literature, e.g., Bortolotti and Miyazono (2015, p. 638), might have its origin in such oscillations. ${ }^{4}$ See also Bortolotti (2016), for an interesting discussion on the psychological and even epistemic benefits of reaching this illusory understanding.
} 


\section{REFERENCES}

Angermeyer, M. C., \& Matschinger, H. (2003). Public beliefs about schizophrenia and depression: similarities and differences. Social Psychiatry and Psychiatric Epidemiology, 38 (9), 526-534.

Bentall, R. P. (2004). Madness Explained. Psychosis and Human Nature. London: Penguin Books.

(2010). Doctoring the Mind: Why psychiatric treatments fail. London: Penguin Books.

Bortolotti, L. \& Miyazono, K. (2015). Recent work on the nature and development of delusions. Philosophy Compass, 10/9, 636-645.

Bortolotti, L. (2016). Epistemic benefits of elaborated and systematized delusions in schizophrenia. British Journal for the Philosophy of Science, 67 (3), 879-600.

Campbell, J. (2001). Rationality, meaning and the analysis of delusion. Philosophy, Psychiatry \& Psychology, 8 (2/3), 89-100

Coltheart, M., Menzies, P., \& Sutton, J. (2010). Abductive inference and delusional belief. Cognitive Neuropsychiatry, 15 (1-3), 261-287.

Comstock, G. (2013). Research Ethics. A philosophical guide to the responsible conduct of research. Cambrdige: Cambridge University Press.

Crocket, Z. (2015, February 19). The time everyone "corrected” the world's smartest woman. Priceonomics. https://priceonomics.com/the-time-everyone-corrected-the-worlds-smartest/ Davies, M., Coltheart M., Langdon, R. \& Breen, N. (2001). Monothematic delusions: Towards a two-factor account. Philosophy, Psychiatry \& Psychology, 8 (2/3), 133-158.

Ellis, H. D., \& Young, A. W. (1990). Accounting for Delusional Misidentifications. The British Journal of Psychiatry, 157 (2), 239-248.

Feldman, R. (2004). Freedom and Contextualism, in J. K. Campbell, M. O’Rourke, \& D. Shier (Eds.) Freedom and Determinism (pp. 255-276). Cambridge, Massachusetts: MIT Press.

Frame, J. (1961). Faces in the Water. Christchurch: Pegasus Press.

Glover, J. (2014). Alien landscapes? Interpreting Disordered Minds. London: The Belknap Press of Harvard University Press.

Henriksen, M. G. (2013). On Incomprehensibility in Schizophrenia. Phenomenology and the Cognitive Sciences 12 (1), 105-129.

Jaspers, K. (1997). General Psychopathology. London: The John Hopkins University Press 
Kennett, J. (2009). Mental Disorder, Moral Agency and the Self. In B. Steinbock (Ed.)

The Oxford Handbook of Bioethics (pp. 90-113). Oxford: Oxford University Press.

Kirschenbaum, H., \& Jourdan, A. (2005). The Current Status of Carl Rogers and the Person

Centered Approach. Psychotherapy: Theory, Research, Practice, Training. 42 (1), 37-51.

Maher, B. A. (1999). Anomalous experiences in everyday life: its significance for psychopathology. Monist. 82 (4), 547-571.

Nahmias, E. (2011). Intuitions about Free Will, Determinism and Bypassing, in Robert Kane (Ed.) the Oxford Handbook of Free Will, Second Edition, (pp. 555-576). Oxford: Oxford University Press.

Nagel, T. (1974). What it is like to be a bat? The Philosophical Review. 83 (4), 435-450.

Pescosolido, B. A., Martin, J. K., Long, J.S., Medina, T. R., Phelan, J. C., \& Link, B. G. (2010). “A Disease Like Any Other”? A Decade of Change in Public Reactions to Schizophrenia, Depression, and Alcohol Dependence. American Journal of Psychiatry. 167 (11), 1321-1330.

Read, J. \& Harré, N. (2001). The role of biological and genetic causal beliefs in the stigmatisation of 'mental patients'. Journal of Mental Health. 10 (2), 223-235.

Reed, G. (1974). The Psychology of Anomalous Experience: A Cognitive Approach. Boston: Houghton Mifflin.

Rhodes, J. \& Gipps, R. G. T. (2008). Delusions, Certainty and the Background. Philosophy, Psychiatry \& Psychology. 15 (4), 295-310.

Rogers, C. R. (1957). The necessary and sufficient conditions of therapeutic personality change. J. consult. Psychol., 21 (2), 95-103.

(1965). The therapeutic relationship: Recent theory and research. Austrian Journal of Psychology. 17 (2), 95-108.

Sass, L. (2013). Jaspers, phenomenology, and the 'ontological difference'. In G.

Stanghellini, and T. Fuchs (Eds.), One century of Karl Jaspers' General

Psychopathology (pp. 95-106). Oxford: Oxford University Press.

Schnittker, J. (2008). An uncertain revolution: Why the rise of a genetic model of mental illness has not increased tolerance. Social Science and Medicine. 67, 1370-1381

Searle, J. (1983). Intentionality. Cambridge: Cambridge University Press.

Shtulman, A. (2015). How lay cognition constrains scientific cognition. Philosophy

Compass. 10/11, 785-798

Stammers, S. \& Pulvermacher, R. (2020). The value of doing philosophy in mental health contexts. Medicine, health care and society. https://doi.org/10.1007/s11019-020-09961-4 
Stanghellini, G. (2013). The ethics of incomprehensibility. In G. Stanghellini and T.

Fuchs (Eds.) One century of Karl Jaspers' General Psychopathology, (pp. 166-181).

Oxford: Oxford University Press.

Steup, M. \& Neta, R. "Epistemology", The Stanford Encyclopedia of Philosophy (Fall 2020

Edition), Edward N. Zalta (ed.), forthcoming URL =

$<$ https://plato.stanford.edu/archives/fall2020/entries/epistemology/>. Article referred to, on

August 12 https://plato.stanford.edu/entries/epistemology/\#GeneSkepSeleSkep

Strawson, P. F. (1962). Freedom and Resentment. Proceedings of the British Academy. 48, 125 .

Trout, J. L. (2016). Wondrous Truths. The improbable triumph of modern science. New York:

Oxford University Press.

Upthegrove, R. \& S.A. (2008). Delusional beliefs in the clinical context. In L. Bortolotti (Ed.)

Delusions in context (pp. 1-26). Palgrave Macmillan.

Watts, J. \& Priebe, S. (2002). A Phenomenological Account of User's Experiences of Assertive Community Treatment. Bioethics. 16 (5), 439-54

Wittgenstein, L. (1969). On Certainty. Oxford: Basil Blackwell. 